\title{
Review article: Simulation in anesthesia: state of the science and looking forward
}

\section{Article de synthèse: La simulation en anesthésie: état de la science et perspectives d'avenir}

\author{
Vicki R. LeBlanc, PhD
}

Received: 12 July 2011/Accepted: 16 November 2011/Published online: 17 December 2011

(C) Canadian Anesthesiologists' Society 2011

\begin{abstract}
Purpose Within the field of anesthesia, simulation has been used as a tool for training and assessment for over 30 years. The purpose of this review is to evaluate the state of the science in terms of its effectiveness as an approach to both training and assessment in anesthesia. Articles in the area of simulation and anesthesia published up to and including 2011 were reviewed for inclusion in this narrative review.

Principal findings Simulation-based training is generally well received by participants, it can lead to improved performance in subsequent simulation events, and some transfer of learning to the clinical setting is evident. There is also some early evidence that well-designed performance assessments could have the required reliability and validity to support high-stakes examinations. However, further work is needed in order to set standards and establish the predictive validity to support such assessments.

Conclusion For simulation to realize its potential impact, further research is needed to understand how to optimize this modality of learning more effectively, how to transfer knowledge of research findings to practice, and also how to broaden the simulation modalities used in anesthesia. In future, the optimal use of simulation will depend on a clear understanding of what can and cannot be accomplished with simulation and its various modalities.
\end{abstract}

\section{Résumé}

Objectif Dans le domaine de l'anesthésie, la simulation est utilisée depuis plus de trente ans comme outil de

V. R. LeBlanc, PhD ( $₫)$

Wilson Centre, University of Toronto, 200 Elizabeth Street,

1ES-565, Toronto, ON M5G 2C4, Canada

e-mail: Vicki.leblanc@utoronto.ca formation et d'évaluation. L'objectif de cette synthèse est d'évaluer l'état de cette science en termes d'efficacité en tant qu'approche à la formation et à l'évaluation en anesthésie. Nous avons passé en revue pour inclusion dans ce compte-rendu narratif les articles dans les domaines de la simulation et de l'anesthésie publiés jusqu'à 2011 inclusivement.

Constatations principales La formation basée sur la simulation est, en règle générale, bien reçue par les participants; elle peut ameliorer la performance lors d'évènements subséquents de simulation, et un certain transfert des connaissances acquises à la pratique clinique est évident. Certaines données probantes précoces indiquent aussi que les évaluations de performance bien conçues pourraient posséder la fiabilité et la validiténécessaires à la constitution d'examens à enjeux importants. Toutefois, des travaux supplémentaires sont nécessaires afin d'établir des normes et de déterminer la validité prédictive avant de pouvoir recommander de telles évaluations.

Conclusion Pour que la simulation réalise son impact potentiel, des recherches supplémentaires sont nécessaires afin de comprendre comment maximiser cette modalité d'apprentissage de manière encore plus efficace, comment transférer à la pratique les connaissances tirées de résultats de recherche, et comment élargir les modalités de simulation utilisées en anesthésie. À l'avenir, l'utilisation optimale de la simulation dépendra d'une bonne compréhension de ce qui peut ou non être réalisé à l'aide de la simulation et de ses diverses modalités.

In its most diverse forms, simulation refers to the re-creation of something real by imitation. In medical education, simulation can refer to a number of modalities used to re-create some component of the clinical encounter for the 
purposes of training or assessment, including part-task trainers, virtual reality simulators, standardized patients, virtual patients, and computerized full-body mannequins. ${ }^{1-5}$ Simulation in the form of standardized patients and early full-body mannequin simulators has been described in the healthcare literature since the late 1960s. ${ }^{6-8}$ However, its broader acceptance into medical education can be dated closer to the turn of the 21 st century with the formation of the Association of Standardized Patients in $1991,{ }^{9}$ the first International Meeting on Simulation in Healthcare in $1995,{ }^{10}$ the establishment of the Society for Simulation in Healthcare in $2004,{ }^{10}$ and the publication of Simulation in Healthcare beginning in 2006. ${ }^{11}$

The growing acceptance of simulation in healthcare training has been attributed to the decreased availability and acceptance of practising skills on patients, the growth in technology, which has fuelled the development of increasingly sophisticated simulation modalities, as well as the development of a culture of safety, which has resulted in decreased tolerance for errors. ${ }^{3,5,12-15}$ Together, these forces have led to greater interest and expertise in the development of simulation-based training modalities to re-create teaching and assessment opportunities where practice or assessment on real patients is either not feasible or undesirable.

In anesthesia, the first systematic use of simulation for training consisted of full-body mannequin simulators placed in simulated clinical environments to train students, residents, and staff physicians in managing operative and perioperative acute events. The development of the fullbody mannequins that are currently used for training and assessment date back to the mid-1980s with the CAE-Link simulator developed at Stanford University by Gaba et al. ${ }^{16}$ and the Gainesville Anesthesia Simulator developed by Good and Gravenstein at the University of Florida in Gainesville. ${ }^{5,14,17}$ Although the two groups had different approaches for simulation-based training, they both targeted the recognition of anesthetic critical events and their management. ${ }^{5,18}$ Gaba's work on team training, Simulation-Based Training in Anesthesia Crisis Resource Management (ACRM), has had a marked impact on simulation-based training in anesthesia. Patterned after the Crew Resource Management system from the field of aviation, ACRM is currently the predominant model for training anesthesiologists and trainees to manage operative and perioperative crises. ${ }^{19}$

The ACRM curriculum developed by Gaba et al. consisted primarily of highly realistic simulation scenarios in which participants managed acute events. These events were followed by detailed video-assisted debriefing sessions during which the medical and technical elements and the principles of crisis management (leadership, teamwork, workload distribution, resource utilization, re-evaluation, and communication) were covered. By the mid-1990s, ACRM training had spread to other anesthesia simulation programs across the United States and Canada. ${ }^{16,20}$ Crisis management training and related approaches, generally described as team or non-technical skills training for high acuity events, spread rapidly across North America and Europe and now represent the bulk of anesthesia simulation-based training. $8,19,21,22$

More recently, the use of simulation in anesthesia has broadened to include the acquisition of technical skills (e.g., fibreoptic oral intubations and cricothyroidotomies), ${ }^{23-26}$ the study of performance-shaping factors and performance gaps, ${ }^{27-34}$ the evaluation of new equipment, ${ }^{35}$ and modelling patient flow in clinical settings. ${ }^{36,37}$

\section{Simulation for training: state of the science}

\section{Changes in learner perceptions}

Early research on the impact of simulation-based training targeted the perceptions of participants. The results of these studies showed that participants were generally very positive about their training, and they perceived their training as contributing to safe practice. ${ }^{38-44}$ However, a few studies also showed that this form of education was intimidating and stressful for participants, ${ }^{41}$ and only a minority $(\sim 30 \%)$ believed it had influenced their clinical practice. ${ }^{45,46}$ Interestingly, there is also a growing body of evidence showing that self-reports of participants do not predict their actual levels of performance. ${ }^{47,48}$ While simulation is generally well received by trainees, these results together indicate that this acceptance is not universal. Therefore, educators seeking to use simulation should carefully construct sessions that create safe learning experiences for the trainee. Also, given the growing body of work showing that perceptions of learning do not always predict actual learning, research aimed at assessing the impact of learning modalities cannot rely simply on the learners' perceptions of learning. While learner perceptions can be useful to determine how a simulation session was received and experienced, they are not sufficient to determine whether the session actually enhanced, impaired, or had no effect on learning.

\section{Evidence for effectiveness of simulation-based learning}

Beyond showing that crisis management training is generally well received and perceived as beneficial for training, it is essential to demonstrate that this resource intensive training can also improve learning and clinical performance compared with more traditional forms of 
instruction. A number of studies on the effectiveness of simulation-based training have used performance during simulated critical events as outcome measures, in large part due to the challenges of measuring performance in clinical settings. Chopra et al. ${ }^{49}$ showed that anesthesiologists trained to manage malignant hyperthermia with a full-body mannequin simulator responded more quickly, deviated less from accepted guidelines, and performed better in handling a subsequent simulated malignant hyperthermia than residents who did not receive the training. Yee et al. ${ }^{50}$ showed that a single simulation session constructed around an ACRM-type course improved non-technical skills (i.e., decision-making, situation awareness, and interpersonal skills) of residents during a simulated anesthesia crisis. In a study with practicing anesthesiologists, Morgan et al. ${ }^{51}$ showed that mannequin-based simulation with debriefing led to improvements in some aspects of the clinical management of simulated critical events up to nine months after the training. In a comparison with baseline, Kuduvalli et $a l .{ }^{52}$ demonstrated that anesthesiologists with simulation-based training subsequently demonstrated a more structured approach and reduced equipment misuse during simulated difficult airway scenarios. Schwid et al. ${ }^{53} \mathrm{dem}-$ onstrated that residents who had received screen-based anesthesia training subsequently managed mannequinbased anesthetic emergencies better than residents who studied a handout covering the same content.

Although studies have shown enhanced learning following simulation-based sessions, a number of studies have failed to show improvements. Olympio et al. ${ }^{54}$ did not show improvement in anesthesia residents' management of esophageal intubation following simulation-based training. Borges et al. ${ }^{55}$ did not observe significant changes in practicing anesthesiologists' airway management of a "cannot intubate, cannot ventilate" simulated scenario following simulation training. Wenk et al. ${ }^{56}$ compared simulation-based learning with problem-based learning on anesthesia students' ability to perform a rapid sequence intubation on a full-body mannequin. Following the training session, students in both groups performed equally well on the rapid sequence intubation task. However, the students who received the simulation-based training were significantly more confident regarding their knowledge of rapid sequence intubations.

A troublesome finding from the research is that participation in a simulation-based session can increase trainees' confidence and perceived abilities without necessarily enhancing their true abilities. This overinflated sense of confidence can be counterproductive if it leads trainees to stop practising because they mistakenly believe they have reached an acceptable level of competency. It can be dangerous if this overconfidence leads trainees to take on clinical challenges for which they, in fact, do not have the required skills. This finding raises the issue regarding the degree of responsibility that educators must bear in terms of providing trainees accurate information as to their levels of competency following simulation sessions.

\section{Transfer of learning to the clinical setting}

In addition to using simulated scenarios to study the outcomes of simulation-based training on simulated tasks, researchers have recently studied the transfer of learning to the clinical setting. There is accumulating evidence that well-designed simulation-based training can translate to improved performance in the clinical setting for both technical tasks ${ }^{23,57,58}$ and management of high-acuity events. $^{59,60}$ In a prospective single-blinded randomized controlled trial on weaning from cardiopulmonary bypass, Bruppacher et al. ${ }^{61}$ observed that simulation-based training led to improved performance in a real clinical setting compared with interactive seminars. In a study of central venous line insertions in intensive care units, Barsuk et $a .^{62,63}$ observed that mastery-level simulation training led to higher success rates as well as reduced rates of infections with real patients. Wayne et al. ${ }^{59}$ observed that simulation-trained residents adhered more closely to Advanced Cardiac Life Support (ACLS) guidelines during actual cardiac events than their traditionally trained counterparts.

\section{Key elements in simulation-based learning}

While learning can be enhanced with simulation sessions, the research on simulation-based learning shows that there are cases in which this does not occur. As such, it is not possible to state that simulation, as a broad approach, is effective or ineffective for learning. Rather, simulation sessions can be conducted in a number of different ways; some simulation sessions will be more effective than other methods of learning, and other simulation sessions will not be more effective. Those elements that lead to enhanced learning are not necessarily inherent to simulation itself. Therefore, it is important to understand the elements in simulation-based sessions that facilitate learning, as well as how to optimize learning using this form of practice and instruction. There has been a growing body of research aimed at a better understanding of the mechanisms that optimize simulation-based training.

\section{Debriefing}

Debriefing has been shown to be a critical element in the observation of improved performance following 
simulation-based training. ${ }^{64,65}$ However, the format used for the instruction or debriefing following the simulation scenario does not appear to have a significant effect on learning. Anesthesia students showed similar improvements in post-scenario debriefing sessions whether with a simulator or with a video session facilitated by faculty. ${ }^{66}$ In simulated ACLS resuscitation scenarios, Welke et $a l^{67}$ showed that multimedia instruction and facultyled video-assisted debriefing sessions led to similar improvements. Boet et al. ${ }^{68}$ reported similar results when comparing self-debriefing with instructor debriefing. These early studies suggest that the format in which debriefing is delivered may have a minimal impact on subsequent learning. However, more research is needed to understand more clearly the contributions of format and delivery mechanisms on the effectiveness of debriefing.

In addition to studying the format in which debriefing is delivered, researchers have explored whether the content and structure of debriefing has an impact on learning. Park et al. ${ }^{69}$ have shown that the improvements observed following simulation-based training appear to be content specific. In their study with anesthesia residents, they demonstrated that event-specific simulation training resulted in subsequent improved performance compared with simulation-based training in an alternate event. Residents who had received training on hypoxemia subsequently performed better during simulated hypoxemic events but not during scenarios related to hypotension. In contrast, those residents who received training on hypotension subsequently performed better during hypotension-related scenarios but not on scenarios related to hypoxemia. Looking at the structure of debriefing, Johnson et al. ${ }^{70}$ compared different teaching approaches with simulationbased training. Over a 12-month period, anesthesia residents were assigned to either a control group that received standard didactic and simulation-based training or to an experimental group that received similar training but with an emphasis on part-task training (dividing tasks into components) and variable priority training (focus on optimal distribution of attention when performing multiple tasks simultaneously). The group receiving the part-task and variable priority training showed more improvements in performance when managing adverse airway and respiratory events.

While debriefing (or feedback) serves an important role in the effectiveness of simulation-based training, these results together suggest that it is a complex process. According to the research to date, the format in which debriefing is delivered (simulation-based, instructor-led, multimedia, or self-led instruction) does not seem to impact learning. However, the work of researchers, such as Johnson et $a l .{ }^{70}$ and Park et al. ${ }^{69}$ suggests that the content and the structure of the debriefing or feedback may play an important role in learning.

\section{Fidelity}

Another important area of inquiry regarding the key elements of simulation is fidelity. In light of the high monetary and personnel resources that are invested into full-body mannequin simulations, some researchers have investigated whether lower-fidelity lower-cost simulations could be as effective as the higher-cost higher fidelity simulations. Nyssen et $a l^{71}$ compared the effectiveness of a computer screen-based simulator with a mannequinbased simulator for training novice and experienced anesthesia residents in the management of simulated anaphylactic shock. They found that the two types of simulators did not result in significant differences in learning. High-fidelity and low-fidelity simulators can have equally positive impacts on learning for novice students. ${ }^{24,72-74}$ Hence, the purchase of high-cost high-fidelity simulators must be considered thoughtfully, especially for use early in the learning curve. Moreover, rather than comparing low-fidelity with high-fidelity simulators, new studies have suggested that a better approach may be to structure the simulation experience as a progressive training program. ${ }^{75}$ In addition, recent work regarding the concepts of fidelity and realism ${ }^{76-78}$ suggests that these are complex concepts that extend beyond the physical realism of the mannequin, and more work is needed to understand fully what we mean by fidelity and the role it plays in simulation-based training.

\section{Simulation for team training}

Although the bulk of the research has focused on teaching non-technical or crisis management skills to individuals, there is a small but growing body of work targeted towards team training. ${ }^{22}$ Teamwork dysfunction has been associated with decreased quality of care, such as increased adverse events and poor patient outcomes. ${ }^{79,80}$ This has led to a growing interest in collective competency, moving beyond teaching individuals alone towards also teaching team coordination and communication skills to interprofessional teams. Most of the literature to date has focused on the development and deployment of such training ${ }^{69,81}$ based on approaches that have been successful in other high-risk domains such as aviation and the military. ${ }^{82}$ Although self-reports from participants indicate that they credit the training for increasing their teamwork skills, ${ }^{83-85}$ thus far, there is little research in anesthesia investigating the effectiveness of this form of training on the behaviours and clinical practice of teams. 


\section{Simulation for assessment: state of the science}

In addition to interest and research in the use of simulation for training, there is continued interest in the use of simulation modalities for assessment and certification. ${ }^{86}$ For more than ten years, simulation-based scenarios have been incorporated into the Israel Board Examination in Anesthesia. ${ }^{87,88}$ More recently, the American Board of Anesthesiology has incorporated mandatory simulationbased activities in the ten-year maintenance of certification cycle ${ }^{89,90}$ and the Royal College of Physicians and Surgeons of Canada has introduced a simulation-assisted oral station in the 2010 anesthesia examination. ${ }^{91}$ Although the use of simulation for formative assessments is widely accepted, the use of simulation for summative assessments remains somewhat contentious, and developments are slower than those in the use of simulation for training purposes.

One reason for this interest in simulation for assessment and certification is that they are viewed as being authentic assessments of the cognitive and behavioural components of competency. ${ }^{92}$ While workplace-based assessments are highly desirable for the assessment of competency, concerns have been raised about the psychometric properties of this form of assessment. ${ }^{93,94} \mathrm{In}$ contrast, while methods such as written examinations and oral examinations have solid psychometric properties, they are critiqued for lacking ecological validity, i.e., for not closely re-creating the practice conditions under which we want to assess competency. ${ }^{95,96}$ Simulation-based assessments have been proposed as complementary means to assess performance and behaviour in an authentic and reliable context. ${ }^{65,86}$

\section{Assessing individual performance}

The interest in the use of simulation for the assessment of performance has fostered significant research. Several review papers have presented overviews of the literature and have included recommendations regarding the appropriateness of using simulation in high-stakes examinations. ${ }^{97,98}$

Recently, Boulet and Murray ${ }^{99}$ wrote a broad narrative review on the use of simulation for assessment and the implications of such assessments on anesthesiology. They also included a thoughtful discussion of important considerations for educators looking to develop valid and reliable simulation-based assessments.

Boulet and Murray ${ }^{99}$ report that, thus far, most of the work examining the reliability of simulation-based assessments had focused on inter-rater agreement as well as the consistency of examinee scores across multiple stations or scenarios. Different tasks and assessment contexts were associated with varying levels of inter-rater agreement, with ratings of teams and non-technical skills often having lower inter-rater agreement than assessments of individual technical skills or clinical management. As for the consistency of scores across cases or scenarios, these were generally low due to the content specificity of knowledge and skills. These findings are consistent with the vast literature on assessments of performance, which show that clinical competence is very content-specific. ${ }^{95,100}$ Strong performance in one aspect of competency does not imply that a candidate will perform equally well in other aspects of competency. ${ }^{86}$ As such, multiple stations (8-15) were recommended in order to ensure that the scores obtained are reliably precise enough for an examiner to make decisions regarding an examinee's level of competence. ${ }^{99,101-104}$

Boulet and Murray ${ }^{99}$ also discussed research into the validity of simulation-based assessments. To date, most of the work towards making inferences regarding the validity of simulation-based examinations has been directed towards content validity, i.e., seeking to ensure that simulation scenarios are modelled and scripted based on actual practice characteristics. However, for simulation-based assessments to become fully integrated into summative evaluations of performance, significantly more work is needed in terms of establishing standards and demonstrating that simulation-based performance is predictive of future performance in clinical settings.

\section{Assessing team performance}

More recently, there has been growing interest in assessing team performance. This development is in response to studies and reports showing that a high percentage of errors in the operating room could be attributed to gaps in team coordination and communication. One initial challenge in team assessment was the absence of valid and reliable tools to evaluate group performance. There has been significant work in recent years aimed at the development and evaluation of such tools. ${ }^{105-110}$ To date, there have been contradictory results regarding the validity of these tools, suggesting that more refinements are needed before the field is ready for high-stake assessments of teams. ${ }^{109}$ The implications relating to summative assessments of team performance present a second challenge. If a team were to fail on a simulated summative assessment, what implications would there be for the individual team members, for the team itself, and for the institution? Before the field of anesthesia implements summative assessments of teams, it will need to grapple with such questions. 


\section{Looking forward: advancing the field and optimizing the use of simulation}

Looking at the current state of simulation, the question is no longer whether simulation will have a lasting presence in the education of the health professions. Licensing bodies in the United States and Canada now mandate the use of simulation in certain specialties, ${ }^{3}$ and accreditation standards for simulation programs are being developed and rolled out internationally. ${ }^{111-113}$ However, this does not mean that the work is done. The following section deals with aspects of simulation that need further refinement or attention if we are to use simulation modalities optimally to enhance current health professional training and practice.

\section{Research}

Anesthesia is one of the specialties in which a significant amount of research has been conducted on the use of simulation for training and assessment. Much of the research has focused on the outcomes of simulation-based training by asking the question, Does it work? The focus of research has been moving gradually from participant reactions, to behaviours and skills, and now towards transfer to the clinical setting and patient outcomes. In addition to this outcomes-based focus, the field also needs research targeted towards gaining a better understanding of simulation by asking the questions: How and why does it work? For whom does it work? and In what context does it work? This type of research is conducted best when grounded in theoretical foundations. For example, although there is growing evidence about the importance of feedback or debriefing, important unanswered questions remain about the most effective method of debriefing. To understand how to provide optimal debriefing and feedback, research is needed that looks at the structure and content of debriefing and is based on decades of inquiry from cognitive and motor learning sciences. ${ }^{22,114,115}$

Research into the effectiveness of simulation has also been directed towards the individual. More recently, however, there has been greater interest in team training and assessment of team performance. In accordance with this greater interest, the field needs additional research that not only explores the effectiveness of team training but also considers the unique challenges that emerge when attempting team training or assessment. ${ }^{116}$

Knowledge translation: uptake of evidence and best practices

Although a significant amount of research has been conducted into the use of simulation in anesthesia and other health professions, only a limited amount of the knowledge acquired through this research is transferred to clinical performance. For example, one of the central tenets attributed to simulation is that it allows for deliberate practice. ${ }^{14,117}$ Deliberate practice is defined as practice undertaken over an extended period of time to attain excellence, and it entails the ongoing efforts required to maintain it. ${ }^{18-120}$ It consists of practising a well-defined task at an appropriate level of difficulty for the individual, informative feedback, and opportunities for repetition and correction of errors. One of the main caveats of deliberate practice is that it consists of repeated practice that occurs over a long period of time. However, with the way that simulation is currently integrated into the curriculum, trainees might participate in simulation-based activities for only a few hours each year. ${ }^{121}$ As such, it is questionable whether this could qualify as deliberate practice.

There is also accumulating evidence of content-specificity of learning and performance. Strong performance in one domain or content area does not predict performance in other domains or content areas. As such, performance is likely to improve only in the specific content domain covered in the simulation activity. To have a true impact on clinical performance, simulation programs would do well to map out the tasks and content of the curricula so as to enhance current simulation-based training and provide instruction across the breadth of these content areas. In view of the research on content-specificity, more study is needed to determine what skills and knowledge are "truly" transferable across content domains and clinical situations.

The uptake of research findings into practice will necessitate a stronger focus on the development and training of simulation instructors and facilitators. Faculty development is one of the least developed aspects of simulation-based training. However, it is a crucial component given that simulation requires a different form of instruction than more traditional didactic-based methods. Faculty development based on evidence and proven theories of learning ${ }^{22}$ will be essential to ensure that we are optimizing a potentially resource intensive and expensive teaching modality.

\section{Broaden the use of simulation}

The focus of simulation education activities appears to be modality driven, and the adoption of any particular simulation modality is strongly associated with the various specialties. For example, the use of standardized patients has been adopted primarily by medicine and family medicine, while the use of task trainers for technical skills remains primarily the domain of surgery. Full-scale mannequin simulations have been the primary form of simulation adopted by anesthesia programs. As a result, the education activities in anesthesia have been mainly those 
that are well adapted to mannequin-based simulation. It is as though the field has found a hammer that works well and has gone forward to look for protruding nails. However, non-technical and crisis management skills, whether at the individual or team level, are not the only important skills of a practicing anesthesiologist. Competent anesthesiologists must also develop excellent technical skills (e.g., central line insertion, endotracheal intubation), patient interaction skills (e.g., preoperative assessments, ambulatory clinics), and clinical reasoning skills. These aspects of performance are not particularly well adapted to the use of full-body mannequins. Rather, technical skills can be accomplished with the use of parttask trainers, patient interaction skills can be learned quite effectively with the use of standardized patients, ${ }^{122,123}$ and clinical reasoning skills can be acquired with virtual patients. ${ }^{124}$ Significant advancements have been made in other disciplines to advance the effective use of simulation for these skills, and the integration and building upon this knowledge in anesthesia could provide a well-rounded use of simulation to enhance skills that are difficult to practise in the actual clinical setting.

\section{Conclusion}

In the past 20 years, there has been significant scholarship devoted to the study of simulation for the purposes of training and assessment. The field of anesthesia has led the way in the use of mannequin-based simulation for training and assessment of non-technical and crisis management skills. The research to date shows that simulation-based training is generally well received by participants. It can lead to improved performance in subsequent simulation events, and some transfer of learning to the clinical setting is evident. There has also been significant interest in the psychometric properties of simulation-based assessments, and there is some early evidence that well-designed performance assessments could have the reliability and validity to support high-stakes examinations. However, further work is needed towards setting standards and establishing the predictive validity to support such assessments. For simulation to reach its potential impact moving forward, further research is needed to understand how to optimize this modality of learning more effectively, how to transfer knowledge from research findings to practice, and how to broaden the simulation modalities used in anesthesia. The question is no longer whether simulation will be used for assessment and training in anesthesia, but how simulation will be implemented and used to its potential. This optimal use will depend on a clear understanding of what can and cannot be accomplished with simulation and its various modalities.

\section{Key points}

- Anesthesia has led the way in the use of mannequinbased simulation for training and assessment of nontechnical and crisis management skills.

- Simulation-based training can lead to improved performance in subsequent simulation events, and some transfer of learning to the clinical setting is evident.

- Further work is needed in the areas of research to understand more clearly how to optimize simulationbased learning.

- Greater focus is needed towards knowledge transfer of research findings to practice.

Competing interests None declared.

\section{References}

1. Alinier $G$. A typology of educationally focused medical simulation tools. Med Teach 2007; 29: e243-50.

2. Doyle DJ. Simulation in medical education: Focus on Anesthesiology. Medical Education Online; 2002. Available from URL: http://www.med-ed-online.org/f0000053.htm (accessed August 2011).

3. Issenberg SB, Scalese RJ. Simulation in health care education. Perspect Biol Med 2008; 51: 31-46.

4. Rall M, Dieckmann P. Simulation and patient safety: the use of simulation to enhance patient safety on a systems level. Curr Anaesth Crit Care 2005; 16: 273-81.

5. Rosen KR. The history of medical simulation. J Crit Care 2008; 23: $157-66$.

6. Denson JS, Abrahamson S. A computer-controlled patient simulator. JAMA 1969; 208: 504-8.

7. Cooper JB, Taqueti VR. A brief history of the development of mannequin simulators for clinical education and training. Postgrad Med J 2008; 84: 563-70.

8. Decker $K$, Rall M. Simulation in anaesthesia: a step towards improved patient safety. Minim Invasive Ther Allied Technol 2000; 9: 325-32.

9. ASPE. Association of Standardized Patient Educators. About ASPE [Internet] 2011. Available from URL; http://www. aspeducators.org/about-aspe.php (accessed August 2011).

10. SSH. Society for Simulation in Healthcare. About SSH [Internet]. Available from URL; http://www.ssih.org/SSIH/ssih/ Home/AboutSSH/Default.aspx (accessed August 2011).

11. Simulation in Healthcare. The Journal of the Society for Simulation in Healthcare [Internet] 2011. Available from URL; http:// journals.lww.com/simulationinhealthcare/pages/default.aspx (accessed August 2011).

12. Lake $C L$. Simulation in cardiothoracic and vascular anesthesia education: tool or toy? Semin Cardiothorac Vasc Anesth 2005; 9: 265-73

13. Okuda Y, Bryson EO, DeMaria S Jr, et al. The utility of simulation in medical education: what is the evidence? Mt Sinai J Med 2009; 76: 330-43.

14. Issenberg SB, McGaghie WC, Hart IR, et al. Simulation technology for health care professional skills training and assessment. JAMA 1999; 282: 861-6. 
15. Bould MD, Naik VN, Hamstra SJ. Review article: New directions in medical education related to anesthesiology and perioperative medicine. Can J Anesth 2012; 59: this issue. DOI: 10.1007/s12630-011-9633-0.

16. Gaba $D$. Simulator training in anesthesia growing rapidly: CAE model born at Stanford. J Clin Monit Comput 1996; 12: 195-8.

17. Bryson EO, Levine AI, Frost EA. The simulation theater: a means to enhanced learning in the 21st century. Middle East $\mathbf{J}$ Anesthesiol 2008; 19: 957-66.

18. Gaba DM, DeAnda A. The response of anesthesia trainees to simulated critical incidents. Anesth Analg 1989; 68: 444-51.

19. Gaba DM, Howard SK, Fish KJ, Smith BE, Sowb YA. Simulation-based training in anesthesia crisis resource management (ACRM): a decade of experience. Simulation \& Gaming 2001; 32: 175-93.

20. Lindekaer AL, Jacobsen J, Andersen $G$, Laub $M$, Jensen PF. Treatment of ventricular fibrillation during anaesthesia in an anaesthesia simulator. Acta Anaesthesiol Scand 1997; 41: 1280-4.

21. Blum RH, Raemer DB, Carroll JS, Dufresne RL, Cooper JB. A method for measuring the effectiveness of simulation-based team training for improving communication skills. Anesth Analg 2005; 100: 1375-80.

22. Glavin R, Flin R. Review article: The influence of psychology and human factors on education in anesthesiology. Can J Anesth 2012; 59: this issue. DOI:10.1007/s12630-011-9634-z.

23. Chandra DB, Savoldelli GL, Joo HS, Weiss ID, Naik VN. Fiberoptic oral intubation: the effect of model fidelity on training for transfer to patient care. Anesthesiology 2008; 109: 1007-13.

24. Friedman Z, You-Ten KE, Bould MD, Naik V. Teaching lifesaving procedures: the impact of model fidelity on acquisition and transfer of cricothyrotomy skills to performance on cadavers. Anesth Analg 2008; 107: 1663-9.

25. Boet $S$, Bould MD, Schaeffer R, et al. Learning fibreoptic intubation with a virtual computer program transfers to 'hands on' improvement. Eur J Anaesthesiol 2010; 27: 31-5.

26. Boet $S$, Naik VN, Diemunsch PA. Virtual simulation training for fibreoptic intubation. Can J Anesth 2009; 56: 87-8.

27. Lorraway PG, Savoldelli GL, Joo HS, Chandra DB, Chow R, Naik VN. Management of simulated oxygen supply failure: is there a gap in the curriculum? Anesth Analg 2006; 102: 865-7.

28. Nyssen $A S$, De Keyser $V$. Improving training in problem solving skills: analysis of anesthesists' performance in simulated problem situations. Travail Humain (Le) 1998; 61: 387-401.

29. Blike GT, Christoffersen K, Cravero JP, Andeweg SK, Jensen J. A method for measuring system safety and latent errors associated with pediatric procedural sedation. Anesth Analg 2005; 101: 48-58.

30. Lighthall GK, Poon T, Harrison TK. Using in situ simulation to improve in-hospital cardiopulmonary resuscitation. Jt Comm J Qual Patient Saf 2010; 36: 209-16.

31. Harrison TK, Manser T, Howard SK, Gaba DM. Use of cognitive aids in a simulated anesthetic crisis. Anesth Analg 2006; 103: 551-6.

32. Mudumbai SC, Fanning R, Howard SK, Davies MF, Gaba DM. Use of medical simulation to explore equipment failures and human-machine interactions in anesthesia machine pipeline supply crossover. Anesth Analg 2010; 110: 1292-6.

33. Zausig YA, Bayer Y, Hacke $N$, et al. Simulation as anditional tool for investigating the performance of standard operating procedures in anaesthesia. Br J Anaesth 2007; 99: 673-8.

34. Morgan PJ, Cleave-Hogg D, DeSousa S, Tarshis J. Identification of gaps in the achievement of undergraduate anesthesia educational objectives using high-fidelity patient simulation. Anesth Analg 2003; 97: 1690-4.
35. Dalley P, Robinson B, Weller J, Caldwell C. The use of highfidelity human patient simulation and the introduction of new anesthesia delivery systems. Anesth Analg 2004; 99: 1737-41.

36. Marcon E, Kharraja S, Smolski N, Luquet B, Viale JP. Determining the number of beds in the postanesthesia care unit: a computer simulation flow approach. Anesth Analg 2003; 96: 1415-23.

37. Marjamaa RA, Torkki PM, Hirvensalo EJ, Kirvela OA. What is the best workflow for an operating room? A simulation study of five scenarios. Health Care Management Science 2009; 12: 142-6.

38. Holzman RS, Cooper JB, Gaba DM, Phillip JH, Small SD, Feinstein D. Anesthesia crisis resource management: real-life simulation training in operating room crises. J Clin Anesth 1995; 7: 675-87.

39. Howard SK, Gaba DM, Fish KJ, Yang G, Sarnquist FH. Anesthesia crisis resource management training: teaching anesthesiologists to handle critical incidents. Aviat Space Environ Med 1992; 63: 763-70.

40. Hart EM, Owen H. Errors and omissions in anesthesia: a pilot study using a pilot's checklist. Anesth Analg 2005; 101: 246-50.

41. Kurrek MM, Fish KJ. Anaesthesia crisis resource management training: an intimidating concept, a rewarding experience. Can J Anaesth 1996; 43(5 Pt 1): 430-4.

42. Garden A, Robinson B, Weller J, Wilson L, Crone D. Education to address medical error - $\mathrm{a}$ role for high fidelity patient simulation. N Z Med J 2002; 115: 133-4.

43. Weller JM, Bloch M, Young S, et al. Evaluation of high fidelity patient simulator in assessment of performance of anaesthetists. Br J Anaesth 2003; 90: 43-7.

44. Leith $P$. Crisis management training helps young anesthesiologist successfully manage mid-air passenger cardiac arrest. J Clin Monit 1997; 13: 69.

45. Russo SG, Eich C, Barwing J, et al. Self-reported changes in attitude and behavior after attending a simulation-aided airway management course. J Clin Anesth 2007; 19: 517-22.

46. Savoldelli GL, Naik VN, Hamstra SJ, Morgan PJ. Barriers to use of simulation-based education. Can J Anesth 2005; 52: 944-50.

47. Morgan PJ, Cleave-Hogg D. Comparison between medical students' experience, confidence and competence. Med Educ 2002; 36: 534-9.

48. Eva K, Regehr G. "I'll never play professional football" and other fallacies of self-assessment. J Contin Educ Health Prof 2008; 28: 14-9.

49. Chopra V, Gesink BJ, De Jong J, Bovill JG, Spierdijk J, Brand $R$. Does training on an anaesthesia simulator lead to improvement in performance? Br J Anaesth 1994; 73: 293-7.

50. Yee B, Naik VN, Joo HS, et al. Nontechnical skills in anesthesia crisis management with repeated exposure to simulation-based education. Anesthesiology 2005; 103: 241-8.

51. Morgan PJ, Tarshis J, LeBlanc V, et al. Efficacy of high-fidelity simulation debriefing on the performance of practicing anaesthetists in simulated scenarios. Br J Anaesth 2009; 103: 531-7.

52. Kuduvalli PM, Jervis A, Tighe $S Q$, Robin NM. Unanticipated difficult airway management in anaesthetised patients: a prospective study of the effect of mannequin training on management strategies and skill retention. Anaesthesia 2008; 63: 364-9.

53. Schwid HA, Rooke GA, Michalowski P, Ross BK. Screen-based anesthesia simulation with debriefing improves performance in a mannequin-based anesthesia simulator. Teach Learn Med 2001; 13: 92-6.

54. Olympio MA, Whelan $R$, Ford RP, Saunders IC. Failure of simulation training to change residents' management of oesophageal intubation. Br J Anaesth 2003; 91: 312-8.

55. Borges BC, Boet $S$, Siu $L W$, et al. Incomplete adherence to the ASA difficult airway algorithm is unchanged after a high-fidelity simulation session. Can J Anesth 2010; 57: 644-9. 
56. Wenk $M$, Waurick $R$, Schotes $D$, et al. Simulation-based medical education is no better than problem-based discussions and induces misjudgment in self-assessment. Adv Health Sci Educ Theory Pract 2009; 14: 159-71.

57. Fried GM, Feldman LS, Vassiliou MC, et al. Proving the value of simulation in laparoscopic surgery. Ann Surg 2004; 240: 518-28.

58. Naik VN, Matsumoto ED, Houston PL, et al. Fiberoptic orotracheal intubation on anesthetized patients: do manipulation skills learned on a simple model transfer into the operating room? Anesthesiology 2001; 95: 343-8.

59. Wayne DB, Didwania A, Feinglass J, Fudala MJ, Barsuk JH, $M c$ Gaghie WC. Simulation-based education improves quality of care during cardiac arrest team responses at an academic teaching hospital: a case-control study. Chest 2008; 133: 56-61.

60. Draycott T, Sibanda T, Owen L, et al. Does training in obstetric emergencies improve neonatal outcome? Br J Obstet Gynaecol 2006; 113: 177-82.

61. Bruppacher HR, Alam SK, LeBlanc VR, et al. Simulation-based training improves physicians' performance in patient care in high-stakes clinical setting of cardiac surgery. Anesthesiology 2010; 112: 985-92.

62. Barsuk JH, McGaghie WC, Cohen ER, Balachandran JS, Wayne $D B$. Use of simulation based mastery learning to improve the quality of central venous catheter placement in a medical intensive care unit. J Hosp Med 2009; 4: 397-403.

63. Barsuk JH, McGaghie WC, Cohen ER, O'Leary KJ, Wayne DB. Simulation-based mastery learning reduces complications during central venous catheter insertion in a medical intensive care unit. Crit Care Med 2009; 37: 2697-701.

64. Issenberg SB, Mcgaghie WC, Petrusa ER, Lee Gordon D, Scalese RJ. Features and uses of high-fidelity medical simulations that lead to effective learning: a BEME systematic review*. Med Teach 2005; 27: 10-28.

65. Savoldelli GL, Naik VN, Joo HS, et al. Evaluation of patient simulator performance as an adjunct to the oral examination for senior anesthesia residents. Anesthesiology 2006; 104: 475-81.

66. Morgan PJ, Cleave-Hogg D, McIlroy J, Devitt JH. Simulation technology: a comparison of experiential and visual learning for undergraduate medical students. Anesthesiology 2002; 96: 10-6.

67. Welke TM, LeBlanc VR, Savoldelli GL, et al. Personalized oral debriefing versus standardized multimedia instruction after patient crisis simulation. Anesth Analg 2009; 109: 183-9.

68. Boet S, Bould MD, Bruppacher HR, Desjardins F, Chandra DB, Naik VN. Looking in the mirror: self-debriefing versus instructor debriefing for simulated crises. Crit Care Med 2011; 39: 1377-81.

69. Park CS, Rochlen LR, Yaghmour E, et al. Acquisition of critical intraoperative event management skills in novice anesthesiology residents by using high-fidelity simulation-based training. Anesthesiology 2010; 112: 202-11.

70. Johnson KB, Syroid ND, Drews FA, et al. Part task and variable priority training in first-year anesthesia resident education: a combined didactic and simulation-based approach to improve management of adverse airway and respiratory events. Anesthesiology 2008; 108: 831-40.

71. Nyssen AS, Larbuisson R, Janssens M, Pendeville P, Mayne A. A comparison of the training value of two types of anesthesia simulators: computer screen-based and mannequin-based simulators. Anesth Analg 2002; 94: 1560-5.

72. Grober ED, Hamstra SJ, Wanzel KR, et al. The educational impact of bench model fidelity on the acquisition of technical skill: the use of clinically relevant outcome measures. Ann Surg 2004; 240: 374-81.

73. Matsumoto ED, Hamstra SJ, Radomski SB, Cusimano MD. The effect of bench model fidelity on endourological skills: a randomized controlled study. J Urol 2002; 167: 1243-7.
74. Sidhu RS, Park J, Brydges R, MacRae HM, Dubrowski A. Laboratory-based vascular anastomosis training: a randomized controlled trial evaluating the effects of bench model fidelity and level of training on skill acquisition. J Vasc Surg 2007; 45: 343-9.

75. Brydges $R$, Carnahan H, Rose D, Rose L, Dubrowski A. Coordinating progressive levels of simulation fidelity to maximize educational benefit. Acad Med 2010; 85: 806-12.

76. Dieckmann $P$, Gaba D, Rall M. Deepening the theoretical foundations of patient simulation as social practice. Simul Healthc 2007; 2: 183-93.

77. Dieckmann P, Manser T, Wehner T, Rall M. Reality and fiction cues in medical patient simulation: an interview study with anesthesiologists. J Cogn Eng Decis Mak 2007; 1: 148-68.

78. Sharma $S$, Boet $S$, Kitto $S$, Reeves $S$. Interprofessional simulated learning: the need for "sociological fidelity". J Interprof Care 2011; 25: 81-3.

79. Manser T. Teamwork and patient safety in dynamic domains of healthcare: a review of the literature. Acta Anaesthesiol Scand 2009; 53: 143-51.

80. Paige JT. Surgical team training: promoting high reliability with nontechnical skills. Surg Clin North Am 2010; 90: 569-81.

81. Wilson KA, Burke CS, Priest HA, Salas E. Promoting health care safety through training high reliability teams. Qual Saf Health Care 2005; 14: 303-9.

82. Salas E, DiazGranados D, Weaver SJ, King $H$. Does team training work? Principles for health care. Acad Emerg Med 2008; 15: 1002-9.

83. Fernandez R, Kozlowski SW, Shapiro MJ, Salas E. Toward a definition of teamwork in emergency medicine. Acad Emerg Med 2008; 15: 1104-12.

84. Paige J, Kozmenko V, Morgan B, et al. From the flight deck to the operating room: an initial pilot study of the feasibility and potential impact of true interdisciplinary team training using high-fidelity simulation. J Surg Educ 2007; 64: 369-77.

85. Undre S, Sevdalis N, Healey AN, Darzi A, Vincent CA. Observational teamwork assessment for surgery (OTAS): refinement and application in urological surgery. World J Surg 2007; 31: 1373-81.

86. Boulet JR, Murray D. Review article: Assessment in anesthesiology education. Can J Anesth 2012; 59: this issue. DOI: 10.1007/s12630-011-9637-9.

87. Berkenstadt H, Ziv A, Gafni N, Sidi A. Incorporating simulationbased objective structured clinical examination into the Israeli National Board Examination in Anesthesiology. Anesth Analg 2006; 102: 853-8.

88. Ziv A, Erez D, Munz Y, et al. The Israel Center for Medical Simulation: a paradigm for cultural change in medical education. Acad Med 2006; 81: 1091-7.

89. McIntosh CA. Lake Wobegon for anesthesia... where everyone is above average except those who aren't: variability in the management of simulated intraoperative critical incidents. Anesth Analg 2009; 108: 6-9.

90. Steadman $R H$. Improving on reality: can simulation facilitate practice change? Anesthesiology 2010; 112: 775-6.

91. Blew P, Muir JG, Naik VN. The evolving Royal College examination in anesthesiology. Can J Anesth 2010; 57: 804-10.

92. Edler AA, Fanning $R G$, Chen MI, et al. Patient simulation: a literary synthesis of assessment tools in anesthesiology. J Educ Eval Health Prof 2009; 6: 3.

93. Miller GE. The assessment of clinical skills/competence/performance. Acad Med 1990; 65: S63-7.

94. Hays $R$, Davies $H$, Beard J, et al. Selecting performance assessment methods for experienced physicians. Med Educ 2002; 36: 910-7. 
95. Swanson DB, Norman GR, Linn RL. Performance-based assessment: lessons from the health professions. Educational Researcher 1995; 24: 5-35.

96. Wass V, Van der Vleuten C, Shatzer J, Jones R. Assessment of clinical competence. Lancet 2001; 357: 945-9.

97. Byrne AJ, Greaves JD. Assessment instruments used during anaesthetic simulation: review of published studies. Br J Anaesth 2001; 86: 445-50.

98. Wong $A K$. Full scale computer simulators in anesthesia training and evaluation. Can J Anesth 2004; 51: 455-64.

99. Boulet JR, Murray DJ. Simulation-based assessment in anesthesiology: requirements for practical implementation. Anesthesiology 2010; 112: 1041-52.

100. Eva KW, Neville AJ, Norman GR. Exploring the etiology of content specificity: factors influencing analogic transfer and problem solving. Acad Med 1998; 73: S1-5.

101. Murray DJ, Boulet JR, Avidan M, et al. Performance of residents and anesthesiologists in a simulation-based skill assessment. Anesthesiology 2007; 107: 705-13.

102. Murray DJ, Boulet JR, Kras JF, McAllister JD, Cox TE. A simulation-based acute skills performance assessment for anesthesia training. Anesth Analg 2005; 101: 1127-34.

103. Murray DJ, Boulet JR, Kras JF, Woodhouse JA, Cox T, McAllister $J D$. Acute care skills in anesthesia practice: a simulation-based resident performance assessment. Anesthesiology 2004; 101: 1084-95.

104. Weller JM, Robinson BJ, Jolly B, et al. Psychometric characteristics of simulation-based assessment in anaesthesia and accuracy of self assessed scores. Anaesthesia 2005; 60: 245-50.

105. Fletcher G, Flin R, McGeorge P, Glavin R, Maran N, Patey $R$. Anaesthetists' Non Technical Skills (ANTS): evaluation of a behavioural marker system. Br J Anaesth 2003; 90: 580-8.

106. Malec JF, Torsher LC, Dunn WF, et al. The Mayo high performance teamwork scale: reliability and validity for evaluating key crew resource management skills. Simulation in Healthcare 2007; 2: 4-10.

107. Morgan PJ, Pittini R, Regehr G, Marrs C, Haley MF. Evaluating teamwork in a simulated obstetric environment. Anesthesiology 2007; 106: 907-15.

108. Thomas EJ, Sexton JB, Helmreich RL. Translating teamwork behaviours from aviation to healthcare: development of behavioural markers for neonatal resuscitation. Quality and Safety in Health Care 2004; 13: i57-64.

109. Wright MC, Phillips-Bute BG, Petrusa ER, Griffin KL, Hobbs $G W$, Taekman JM. Assessing teamwork in medical education and practice: relating behavioural teamwork ratings and clinical performance. Med Teach 2009; 31: 30-8.

110. Cooper S, Cant R, Porter J, et al. Rating medical emergency teamwork performance: development of the Team Emergency Assessment Measure (TEAM). Resuscitation 2010; 81: 446-52.

111. Sachdeva AK, Pellegrini CA, Johnson KA. Support for simulation-based surgical education through American College of Surgeons-accredited education institutes. World J Surg 2008; 32: 196-207.

112. SSIH. Society for Simulation in Healthcare. Accreditation. Available from URL: http://www.ssih.org/SSIH/ssih/Forums/ SSHCommittees/CATS/Certification1/Default.aspx (accessed July 2011).

113. American College of Surgeons. Accreditation, Verification, and Quality Improvement Programs. Available from URL; http://www .facs.org/acsverificationprograms.html (accessed July 2011).

114. Hattie J, Timperley $H$. The power of feedback. Rev Educ Res 2007; 77: 81-112.

115. Salmoni $A W$, Schmidt RA, Walter $C B$. Knowledge of results and motor learning: a review and critical reappraisal. Psychol Bull 1984; 95: 355-86.

116. Manser $T$. Team performance assessment in healthcare: facing the challenge. Simul Healthc 2008; 3: 1-3.

117. Perkins $G D$. Simulation in resuscitation training. Resuscitation 2007; 73: 202-11.

118. Ericsson KA. Deliberate practice and the acquisition and maintenance of expert performance in medicine and related domains. Acad Med 2004; 79: S70-81.

119. Moulaert V, Verwijnen $M G$, Rikers $R$, Scherpbier AJJA. The effects of deliberate practice in undergraduate medical education. Med Educ 2004; 38: 1044-52.

120. Arthur W Jr, Bennett W Jr, Stanush PL, McNelly TL. Factors that influence skill decay and retention: a quantitative review and analysis. Hum Perform 1998; 11: 57-101.

121. Byrick RJ, Naik VN, Wynands JE. Simulation-based education in Canada: will anesthesia lead in the future? Can J Anesth 2009; 56: 273-8.

122. Barrows HS. An overview of the uses of standardized patients for teaching and evaluating clinical skills. AAMC Acad Med 1993; 68: 443-51.

123. Cleland JA, Abe K, Rethans JJ. The use of simulated patients in medical education: AMEE Guide No 42. Med Teach 2009; 31 : 477-86.

124. Cook DA, Triola MM. Virtual patients: a critical literature review and proposed next steps. Med Educ 2009; 43: 303-11. 